\title{
Soybean-chickpea rotation on Vertic Inceptisols II. Long-term simulation of water balance and crop yields
}

\author{
Piara Singh $^{\mathrm{a}}$, G. Alagarswamy ${ }^{\mathrm{a}}$, G. Hoogenboom ${ }^{\mathrm{b}}$, \\ P. Pathak ${ }^{\mathrm{a}}$, S.P. Wani ${ }^{\mathrm{a}, *}$, S.M. Virmani ${ }^{\mathrm{a}}$ \\ anternational Crops Research Institute for the Semi-Arid Tropics (ICRISAT) PO Patancheru 502 324, Andhra Pradesh, India \\ ${ }^{\mathrm{b}}$ The University of Georgia, Griffin, GA, USA
}

Received 13 November 1998; received in revised form 23 June 1999; accepted 2 July 1999

\begin{abstract}
In rainfed agriculture, climatic variability has profound effects on the performance of management systems in improvements of productivity and use of natural resources. A field study was conducted on a Vertic Inceptisol during 19951997 seasons at the ICRISAT Center, Patancheru, India, to study the effect of two landforms, i.e., broadbed-and-furrow (BBF) and flat, and two soil depths (shallow and medium-deep) on crop yield and water balance of a soybean-chickpea rotation. Using two seasons experimental data, a soybean-chickpea sequencing model was evaluated and used to extrapolate the results over 22 years of historical weather records. The simulation results showed that in $70 \%$ of years total runoff for BBF was greater than $35 \mathrm{~mm}$ (range 35-190 mm) compared to greater than $60 \mathrm{~mm}$ (range 60-260 mm) for flat on the shallow soil. In contrast on the medium-deep soil it was greater than $70 \mathrm{~mm}$ (range $70-280 \mathrm{~mm}$ ) for BBF compared to greater than $80 \mathrm{~mm}$ (range 80-320 mm) for the flat landform. The decrease in runoff on BBF resulted in a concomitant increase in deep drainage for both soils. In $70 \%$ of years, deep drainage was greater than $60 \mathrm{~mm}$ (range $60-390 \mathrm{~mm}$ ) for the shallow soil and ranged from 10 to $280 \mathrm{~mm}$ for the medium-deep soil. In $70 \%$ of years, the simulated soybean yields were greater than $2200 \mathrm{~kg} \mathrm{ha}^{-1}$ (range $2200-3000 \mathrm{~kg} \mathrm{ha}^{-1}$ ) and were not influenced by landform or soil depth. In the low rainfall years, yields were marginally higher for the BBF than for the flat landform, especially on the shallow soil. Simulated chickpea yields were higher for the medium-deep soil than for the shallow soil. In most years, marginally higher chickpea yields were simulated for the BBF than for the flat landform on both soil types. In $70 \%$ of years, the chickpea yields were greater than $500 \mathrm{~kg} \mathrm{ha}^{-1}$ (range $500-1500 \mathrm{~kg} \mathrm{ha}^{-1}$ ) for the shallow soil, and greater than $800 \mathrm{~kg} \mathrm{ha}^{-1}$ (range $800-1960 \mathrm{~kg} \mathrm{ha}^{-1}$ ) for the medium-deep soil. Total productivity of soybean-chickpea rotation was greater than $3000 \mathrm{~kg} \mathrm{ha}^{-1}$ (range $3000-4150 \mathrm{~kg} \mathrm{ha}^{-1}$ ) for the shallow soil and greater than $3450 \mathrm{~kg} \mathrm{ha}^{-1}$ (range $3450-4700 \mathrm{~kg} \mathrm{ha}^{-1}$ ) for the medium-deep soil in $70 \%$ of years. These results showed that in most years BBF, landform increased rainfall infiltration into the soil and had marginal effect on yields of soybean and chickpea. Crop yields on Vertic Inceptisols can be further increased and sustained by adopting appropriate rain water management practices for exploiting surface runoff and deep drainage water as supplemental irrigation to crops in a watershed setting. (C) 1999 Elsevier Science B.V. All rights reserved.
\end{abstract}

Keywords: Soybean (Glycine max L.); Chickpea (Cicer arietinum L.); Simulation; Water balance; Crop yields; Sequential model; Vertic inceptisol

\footnotetext{
* Corresponding author. Fax: +91-40-241-239

E-mail address: s.wani@cgiar.org (S.P. Wani)
} 


\section{Introduction}

With the large variability in climatic conditions in the semi-arid tropics (SAT), farmers often need to make tactical or conditional decisions for successful crop production, based on their past experience or additional information that may become available as the cropping season progresses. Any attempt to analyze these conditional decisions through field experimentation in a variable climate would require conducting field experiments over several years to adequately sample the climatic variability. Single crop models for several crop species have been developed and used to evaluate alternative management decisions. Keating et al. (1993) and Alagarswamy and Virmani (1996) showed the potential to apply crop simulation models to assess the risks, i.e., uncertainty in profitable increase in yield, associated with nitrogen fertilizer use in dryland crops. The simulation results indicated that only long-term analysis (25-30 years) is likely to give a clear indication of the risks associated with alternative nitrogen fertilizer application strategies. Since long-term experimental evaluation of conditional or/and alternative management strategies is not possible, crop simulation models can be used to simulate alternative management strategies to evaluate the associated long-term risks.

Growing multiple crops in mixtures or in rotation has remained an integral part of the rainfed agriculture, especially in high risk-prone areas. When cereals are grown in rotation with legumes, cereals derive the benefit of nitrogen from legumes. In a 10-year crop rotation study, Rego and Seeling (1996) showed that grain yield of sorghum following a legume was higher than the grain yield of sorghum following a nonlegume in most years. The legume benefit to sorghum was due to increased nitrogen availability, because this advantage was found only at low nitrogen fertilizer levels. Transfer of such site- and season-specific findings to other locations and evaluation of alternative management strategies is possible using systems simulation models.

Recently several studies have been conducted to simulate cropping systems for several crops, either grown in a mixture or in succession, such as a cerealgrain legume. Caldwell and Hansen (1993) assessed risks associated with upland rice-based cropping system involving rice and soybean. This study showed an overall increase in yields when upland rice was preceded by nitrogen-fixing soybean. Double cropping increased yield but also showed a $40 \%$ chance of negative returns. Timsina et al. (1997) coupled CERES-Rice and -Wheat models and used it to identify the causes for low, unstable yield and to quantify nutrient depletion rates in the intensely grown ricewheat system now common in Indo-Gangetic plains of India. Recently, Probert et al. (1998) provided a status report on the capabilities of the Agricultural Production Systems Simulator (APSIM) modeling framework to simulate legume-cereal systems. They used this framework to simulate the performance of a hypothetical chickpea-wheat rotation on clay soils in Queensland. The legume effect was evident in the amount of soil nitrate available at the time of sowing of next crop. These simulation results also indicated that soil organic matter and nitrogen continuously declined in continuous wheat cropping for 25 years without addition of nitrogen fertilizer. The inclusion of a legume crop in the rotation with wheat considerably reduced the decrease of soil fertility. Bowen et al. (1998) have assembled a basic framework for simulating and analyzing long-term crop sequences using crop models released with DSSAT v3. These added capabilities enhance opportunities to investigate sustainability issues of cereal-legume rotations. Cropping systems simulation models are recent developments and need a rigorous evaluation using results from long-term experiments.

In a companion paper, Singh et al. (1999) reported productivity and resource use efficiency of soybeanchickpea rotation in a two year study on a Vertic Inceptisol. Response of soybean to two landform treatments, i.e., broadbed-and-furrow (BBF) and flat, differed on two soil types (shallow and medium-deep) as well as between two seasons. Soybean yields were higher on the flat landform than on the BBF landform for the medium-deep soil, but were similar for the shallow soil. Similarly, the response of soybean on the two soils was different during the 1995-1996 season, but not during the 1996-1997 season. Chickpea yields during the two post rainy seasons were not affected by landform treatment, but were greater on the mediumdeep soil than on the shallow soil. Rainfall-use efficiency differed between years and soil types. Rainfall differences between the two years had a significant impact on the amount of water available for crop 
production and on the losses by surface runoff and deep drainage. The effect of landform treatments on water retention of the soil profile also varied between the two years. These results showed that year-to-year variability in rainfall had a large impact on crop productivity and resource utilization. Therefore, studies are required across many years to capture these effects and to evaluate the risks associated with each type of management.

An alternative approach is to use simulation models and historical weather records to extrapolate the experimental results across space and time. This approach is expected to add value to the experimental results in terms of evaluating constraints and opportunities for improving natural resources use as well as crop productivity. The objectives of this study were: (1) to evaluate the performance of a simulation of a soybean-chickpea rotation with respect to crop productivity and soil water balance; and (2) to determine the impact of climatic variability on the longterm productivity of the rotation for two different landforms applied to different soil depths. The overall goal of this study is to evaluate the scope for increasing crop productivity and rainfall-use efficiency for soybean-chickpea production system on Vertic Inceptisols.

\section{Materials and methods}

All the required data for testing and evaluation of the soybean-chickpea sequencing model were collected from the field experiments conducted during 1995-1997 at the International Crops Research Institute for the Semi-Arid Tropics (ICRISAT) research center, Patancheru, AP, India. The agronomic details of these field experiments are presented in Singh et al. (1999). The experiment consisted of naturally occurring blocks of a shallow and a medium-deep soil in a Vertic Inceptisol watershed. To these soils, two landform treatments, i.e., broadbed-and-furrow (BBF) and flat, were assigned. Thus the whole watershed consisted of four treatments (hydrological units) which were: (1) flat shallow, (2) BBF shallow, (3) flat medium-deep, and (4) BBF medium-deep. Each hydrological unit was further partitioned into 6-8 plots for growing crops and for detailed observations on various aspects of crop growth and resource use. In these hydrological units, soybean (cv. PK 472) was sown in the rainy season followed by chickpea (cvs. ICCV 2 and ICCC 37) in the post rainy season. The measurements taken in these experiments that are relevant to this paper are briefly described below.

\subsection{Climatic measurements}

Climatic data were recorded daily from the class ' $A$ ' agrometeorological observatory adjoining the watershed, including rainfall, maximum and minimum temperatures, and solar radiation. Additionally, rainfall was recorded with two rainguages (one recording and the other non-recording) in the middle of the watershed area to monitor rainfall intensity and amount and to compare these with the observatory data.

\subsection{Crop phenology}

Vegetative and reproductive development of crops was observed in each treatment. Number of nodes formed on the main branch of soybean and chickpea crops were recorded at two-day intervals. Reproductive stages recorded were: flowering, pod-initiation, full pod, beginning of seed growth, full seed, physiological maturity, and harvest maturity. The crops were considered to have reached a particular growth stage when at least $50 \%$ of the plants had shown that stage of development.

\subsection{Crop growth analysis and yields at harvest}

The procedure for plant sampling from the field for growth analysis was described by Singh et al. (1999). After sub-sampling, the plant components were separated and the leaf area of each sub-sample determined, using a leaf area meter (LI-COR instruments, USA). Then the plant components were transferred to separate paper bags and oven dried at $60^{\circ} \mathrm{C}$ for at least $48 \mathrm{~h}$ and weighed to determine dry weight. Total dry matter production per unit area and its distribution to plant components were determined from the data on total dry matter production from the harvested area and from proportional partitions of dry matter to various plant parts as determined from growth analysis of subsamples. The determination of crop yields at final harvest was also described by Singh et al. (1999). 


\subsection{Analysis of observed data}

Simple means and standard errors of all the growth analysis data, e.g., LAI, total dry matter, pod and seed yields, of both soybean and chickpea crops were calculated using general statistical programs. The means were compared with the values simulated by the soybean and chickpea models.

\subsection{Determination of soil water balance and cultivar parameters}

All data collected on climate, crop growth analysis, crop yields, soil water, and agronomic management were recorded in the minimum data set (MDS) sheets provided by the IBSNAT project (IBSNAT, 1990). These data were retrieved to create files needed for execution of the soybean and chickpea models available in DSSAT v3 (Tsuji et al., 1994). Both the soybean and chickpea models in DSSAT v3 are generic versions of SOYGRO and CHIKPGRO models tested earlier (Boote et al., 1997; Wilkerson et al., 1983; and Singh and Virmani, 1996). The models required that the soil characteristics of the two soil types used in this study were determined to define the soil profile input file. Also, the parameters that define the cultivar characteristics of the soybean and chickpea cultivars, used in this study, had to be determined using experimental data.

Soil water balance parameters were evaluated using the measured runoff and soil moisture dynamics. The depth of rooting was taken as $110 \mathrm{~cm}$ for the shallow soil and $125 \mathrm{~cm}$ for the medium-deep soil. Plant extractable soil water (PESW) capacity of soil was $132 \mathrm{~mm}$ for flat shallow, $135 \mathrm{~mm}$ for BBF shallow, $170 \mathrm{~mm}$ for flat medium-deep, and $190 \mathrm{~mm}$ for BBF medium-deep blocks. The differences in PESW of medium-deep soil under two landforms occurred at depths below $95 \mathrm{~cm}$, which had insignificant effect on growth and yield of crops during the rainy or postrainy seasons. First, the drained upper limit and lower limit of plant extractable soil water for each soil were determined, using the soil water data for each soil layer observed during the 1995 growing season. The parameter that defines the runoff curve numbers (CN2) for each treatment was determined runoff data observed from each hydrological unit. Because the watershed sub-units and landform treatments were stabilizing during the 1995-1996 season, only data from the 1996-1997 season could be used to evaluate the runoff performance of the model. Drainage coefficients (SWCON) and the root distribution functions for each soil profile were also adjusted such that the simulated changes in soil moisture for each layer matched the observed data. The final values of these parameters were determined after several iterations of simulation. Once the runoff and soil water changes were satisfactorily simulated, the other components of water balance were also considered to be simulated accurately (Ritchie, 1998).

The cultivar coefficients for the soybean cultivar PK 472 and the chickpea cultivar ICCC 37 for phenology, growth, and dry matter partitioning were determined with the GENCALC program of DSSAT v3 (Hunt et al., 1993; Hunt and Pararajasingham, 1994) using the 1995-1996 data set. The 19961997 data set was used as independent data set for evaluation of model performance for the same experimental site.

\subsection{Long-term simulation of water balance and crop yields}

Using weather records from 1975 to 1996 for the ICRISAT Center, Patancheru, long-term simulations of water balance and productivity of soybean-chickpea rotation were performed for the four treatments using the crop sequencing model available in DSSAT v3 (Thornton et al., 1995). We hypothesized that productivity of the soybean and chickpea rotation system is affected by depth of soil profile, especially available soil moisture, landform, and weather variability. To exclude the effect of spatial soil variability, the same soil profile characteristics were used in the simulation of both the flat and BBF landform treatments for a given soil type. The only change we made was in runoff curve number, to include the difference in runoff between the flat and BBF landforms. Plant extractable soil water of two soil types of this study was $132 \mathrm{~mm}$ for the shallow soil and $170 \mathrm{~mm}$ for the medium-deep soil. Soil fertility status was considered to be the same over years for each simulation run. The sowing date for soybean and chickpea varied each year as a function of available soil moisture of the seedbed during the sowing window, e.g., the earliest and the latest feasible sowing date. Other management prac- 
tices were considered to be the same as for the 19961997 season experiment.

From the multi-year simulations, the cumulative probabilities or the cumulative density functions (CDF) for crop yields and water balance components were calculated for various management strategies. A strategy was considered to have a stochastic dominance (SD) if its CDF was higher or superior to those of other strategies over the entire probability range 0-1.0 (Anderson et al., 1977).

\section{Results and discussion}

\subsection{Performance of crop models for water balance}

Across treatments, total observed runoff during the rainy season ranged from 134 to $259 \mathrm{~mm}$ (Table ), and was greater for the medium-deep soil than for the shallow soil. Similarly, total runoff for the flat landform treatment was greater than for the BBF landform treatment on both soils. In the initial phase of crop growth, i.e., from 12 July to 26 August, the differences between observed and simulated runoff were greater than during the later part of the season. This may be the result of inter-cultivation and weeding operations, which encouraged rain infiltration into the soil, and therefore, an overestimation of runoff in most of the treatments. The current version of the crop simulation model does not account for the effect of mid-season field operations on the surface runoff parameter. At the end of the rainy season, the differences between the observed and simulated runoff were very small for each treatment indicating that the model is able to simulate total seasonal runoff fairly accurately once the appropriate soil parameters have been determined for the soil and the management practice.

Evaluation of model performance for soil water dynamics is only presented for the medium-deep soil. Simulated soil water content for the soybean crop during the 1996 rainy season were fairly close to the observed pattern for both the flat and BBF landforms (Fig. 1(a)). Soil water content for the chickpea crop grown during the post rainy season were also close to the observed data in the initial phase of crop growth, i.e., up to end of November, but were overestimated afterwards (Fig. 1(b)) These differences in soil water content between simulated and observed data occurred mainly in the subsoil (below $95 \mathrm{~cm}$ soil depth). Inaccurate measurements of soil water content due to increased soil variability with depth or increase in soil evaporation following cracking of drying soil might have contributed to this discrepancy between simulated and measured data. The current version of the crop simulation models does not account for the effect of soil cracking on soil evaporation.

\subsection{Performance of crop models for phenology, crop growth, and yield}

Development of soybean and chickpea was not influenced by soil depth or landform treatments. All

Table 1

Effect of soil depth and landform treatment on observed (O) and simulated (S) runoff during 1996 rainy season

\begin{tabular}{|c|c|c|c|c|c|c|c|c|}
\hline \multirow[t]{3}{*}{ Date } & \multicolumn{8}{|c|}{ Landform treatments } \\
\hline & \multicolumn{2}{|c|}{ Flat shallow } & \multicolumn{2}{|c|}{ BBF shallow } & \multicolumn{2}{|c|}{ Flat medium-deep } & \multicolumn{2}{|c|}{ BBF medium-deep } \\
\hline & $\mathrm{O}$ & $S$ & $\mathrm{O}$ & $\mathrm{S}$ & $\mathrm{O}$ & S & $\mathrm{O}$ & $\mathrm{S}$ \\
\hline & \multicolumn{8}{|c|}{ Cumulative runoff (mm) } \\
\hline Jul 12 & 9 & 9 & 8 & 4 & 8 & 15 & 6 & 10 \\
\hline Jul 14 & 16 & 15 & 15 & 7 & 12 & 23 & 6 & 17 \\
\hline Aug 11 & 35 & 46 & 31 & 28 & 35 & 64 & 27 & 52 \\
\hline Aug 24 & 73 & 90 & 53 & 58 & 74 & 123 & 73 & 102 \\
\hline Aug 26 & 94 & 104 & 62 & 66 & 94 & 141 & 95 & 116 \\
\hline Aug 28 & 105 & 108 & 67 & 68 & 112 & 148 & 114 & 123 \\
\hline Aug 30 & 176 & 172 & 119 & 122 & 226 & 223 & 193 & 191 \\
\hline Sep 17 & 187 & 190 & 125 & 132 & 239 & 248 & 212 & 211 \\
\hline Oct 3 & 200 & 207 & 134 & 143 & 259 & 271 & 232 & 231 \\
\hline
\end{tabular}



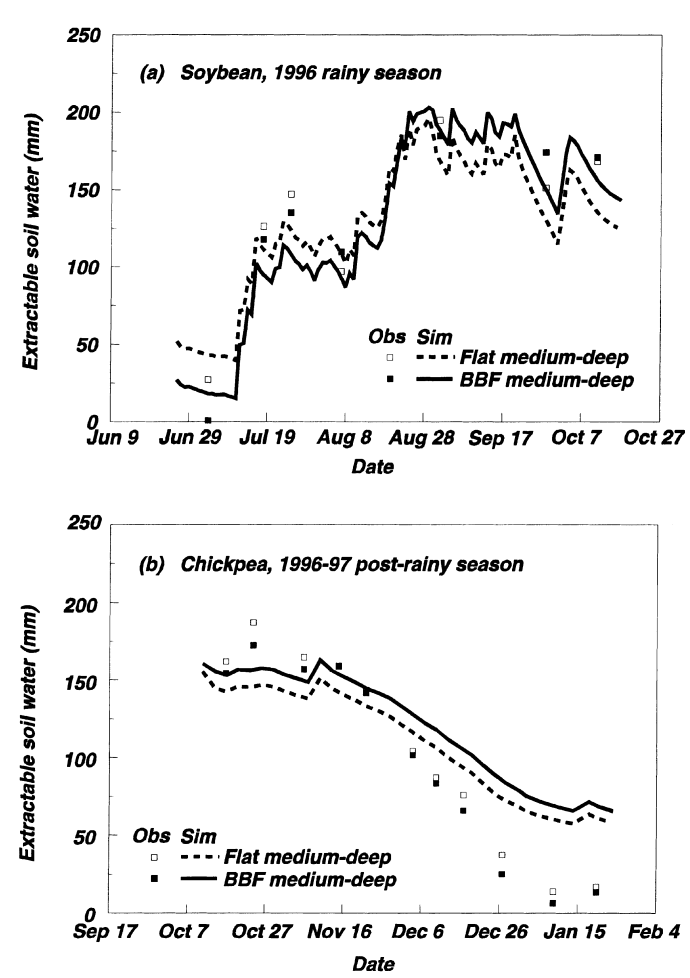

Fig. 1. Simulated (lines) and observed (data points) changes in extractable soil water in the flat and BBF landform treatments for the medium-deep soil during the (a) 1996 rainy and (b) post-rainy seasons.

growth stages for soybean were predicted by the model within \pm 5 days of observed data, except for the beginning of seed growth, which was predicted 12 days after the observed date (Table 2). Prediction of chickpea growth stages was generally earlier than the observed dates; however, physiological maturity of chickpea was within \pm 3 days of observed date.

Leaf area index (LAI) of soybean was greater for the flat landform treatment than for BBF especially on the medium-deep soil; but did not differ between soils (Fig. 2). The differences in LAI are caused by the differences in sowing geometry between the BBF and flat landforms rather than physical factors. The differences in light interception, LAI and crop growth between the flat and BBF landforms were simulated by setting different canopy light extinction coefficients in the model for the two landforms. The temporal changes in simulated LAI were close to the
Table 2

Observed (O) and simulated (S) days after sowing (DAS) to various growth stages of soybean (cv. PK 472) and chickpea (cv. ICCC 37) during 1996-1997 season

\begin{tabular}{lrrrll}
\hline & \multicolumn{2}{c}{ Soybean } & & & \multicolumn{2}{c}{ Chickpea } \\
\cline { 2 - 3 } \cline { 6 - 7 } & \multicolumn{1}{c}{$\mathrm{O}$} & $\mathrm{S}$ & & $\mathrm{O}$ & $\mathrm{S}$ \\
\hline Anthesis & 37 & 38 & & 50 & 43 \\
Pod-initiation & 49 & 51 & & 60 & 54 \\
Beginning seed & 52 & 64 & & 67 & 59 \\
Physiological maturity & 106 & 101 & & 98 & 95 \\
\hline
\end{tabular}

observed data for each treatment prior to peak LAI. During the second part of the growing season LAI was generally overestimated by the model. Simulated LAI was greater for the flat landform treatment than for BBF on both soils. Though the simulated LAI for the

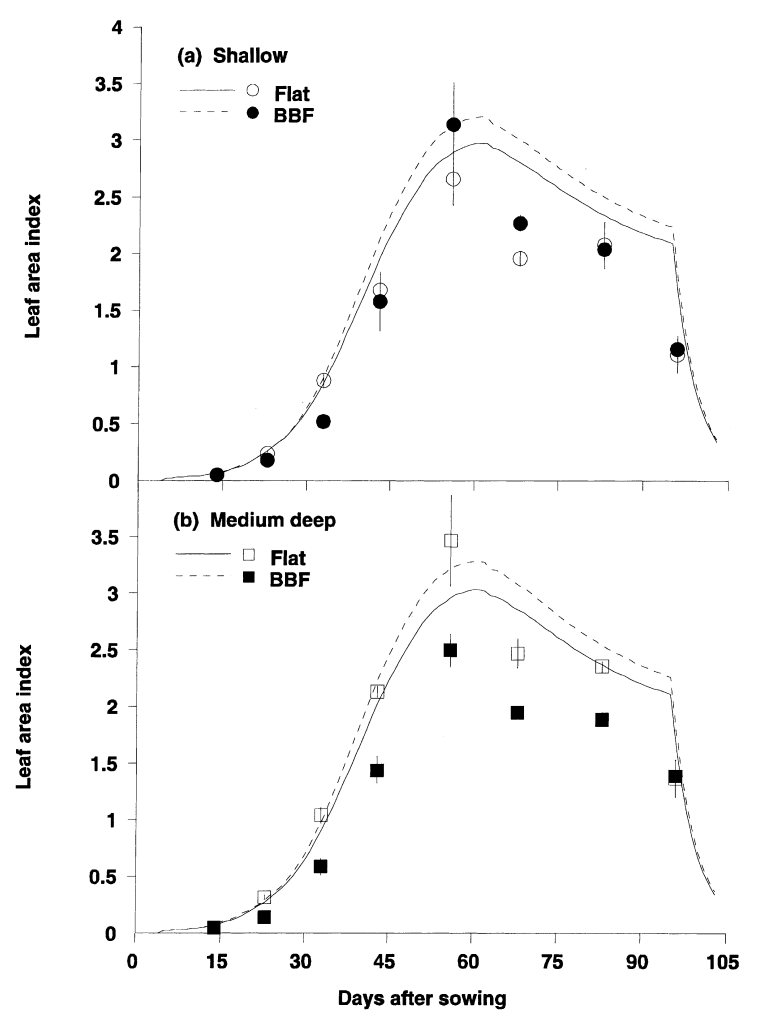

Fig. 2. Simulated (lines) and observed (data points) changes in LAI of soybean in the flat and BBF landform treatments for the (a) shallow and (b) medium-deep soil during the 1996-1997 season. Vertical bars on each data point are double the standard error of mean. 


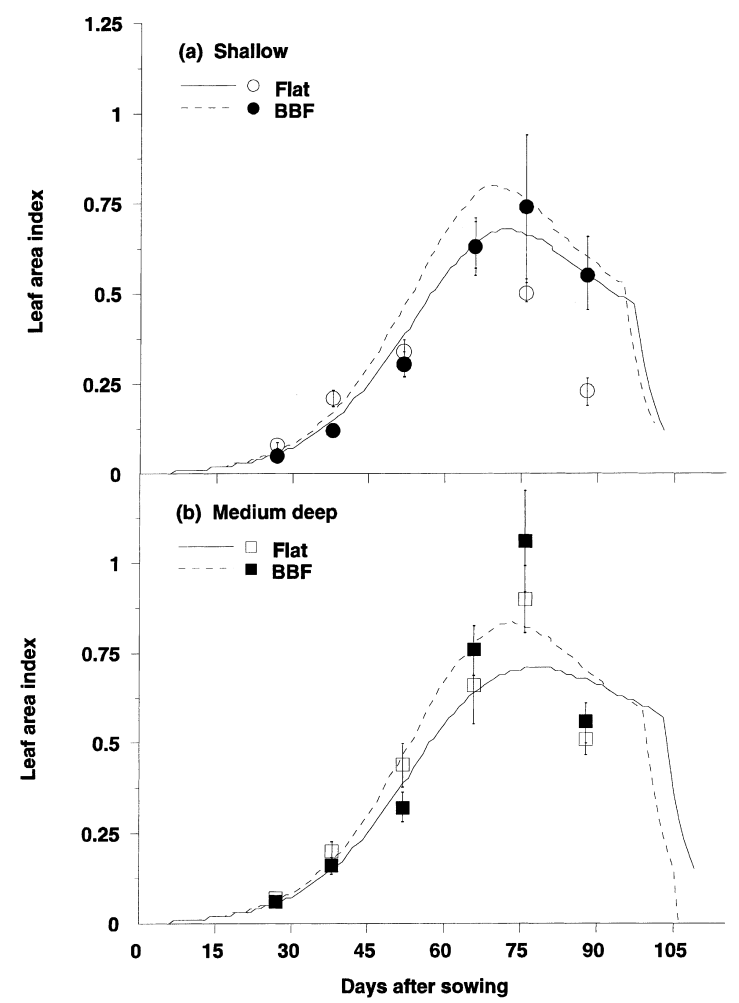

Fig. 3. Simulated (lines) and observed (data points) changes in LAI of chickpea in the flat and BBF landform treatments for the (a) shallow and (b) medium-deep soil during the 1996-1997 season. Vertical bars on each data point are double the standard error of mean.

treatments did not match every observed data point, the differences between the flat and BBF landforms followed the expected pattern. Temporal changes in simulated LAI of chickpea prior to peak LAI were generally close to the observed data for all treatments (Fig. 3). The simulated LAI was greater for the flat landform than for BBF on both soil types, similar to the results for soybean. After the maximum LAI was reached, the decline in observed LAI was much faster than the simulated LAI. In chickpea, leaf senescence occurs rather quickly at the end of growing season and it is difficult to simulate LAI during that phase.

The simulation results showed that crop growth and partitioning of dry matter for soybean during the life cycle were estimated satisfactorily for all treatments (Fig. 4), except that total dry matter was slightly overestimated for the BBF landform treatment for the medium-deep soil. Similar results were obtained in partitioning of total biomass to pods and seeds. For chickpea, the simulation of temporal changes in total biomass and biomass partitioning to pods and seeds was relatively better for medium-deep soil than for shallow soil (Fig. 5). The chickpea model showed a slight overestimation of biomass production after 50 DAS for the shallow soil under extreme stress conditions. Although the model overestimated soil water content, seed and pod yield as well as total biomass at final harvest were accurately estimated for both soils (Fig. 5 and Table 3).

The soybean model slightly overestimated seed yield at final harvest, although dry matter production and partitioning to pods and seeds were fairly accurately simulated (Table 3). One of the discrepancies was caused by the growth analysis samples being taken on small sample plots, while final harvest was conducted on a larger area. In general, the variability for small samples is greater than for large plot samples. Due to extreme wet conditions at harvest maturity, total biomass production and pod yield for soybean were based on samples taken 10 days prior to final harvest. This caused a slight overestimation of pod yield and underestimation of biomass by the model. Simulated biomass, pod and seed yields for the BBF treatment were less than those for the flat landform treatment. In most treatments, the simulated biomass, pod, and seed yields were within $500 \mathrm{~kg} \mathrm{ha}^{-1}$ of observed data, except the biomass yields for the shallow soil. Similarly the simulated biomass and seed yields of chickpea during the post rainy season were within $160 \mathrm{~kg} \mathrm{ha}^{-1}$ of observed data. Part of this difference arose because pod yields were measured four days before final harvest.

The reliable simulation of phenology, temporal changes in LAI, crop growth, partitioning of dry matter, yields at final harvest, and soil water balance indicates that the performance of the soybean-chickpea sequential model is satisfactory and the model can be used with confidence for long-term simulations of the productivity, water balance, and other responses of a soybean-chickpea rotation.

\subsection{Long-term analysis of water balance}

Long-term analysis for Patancheru revealed that rainfall ranged from 450 to $1150 \mathrm{~mm}$ during the 


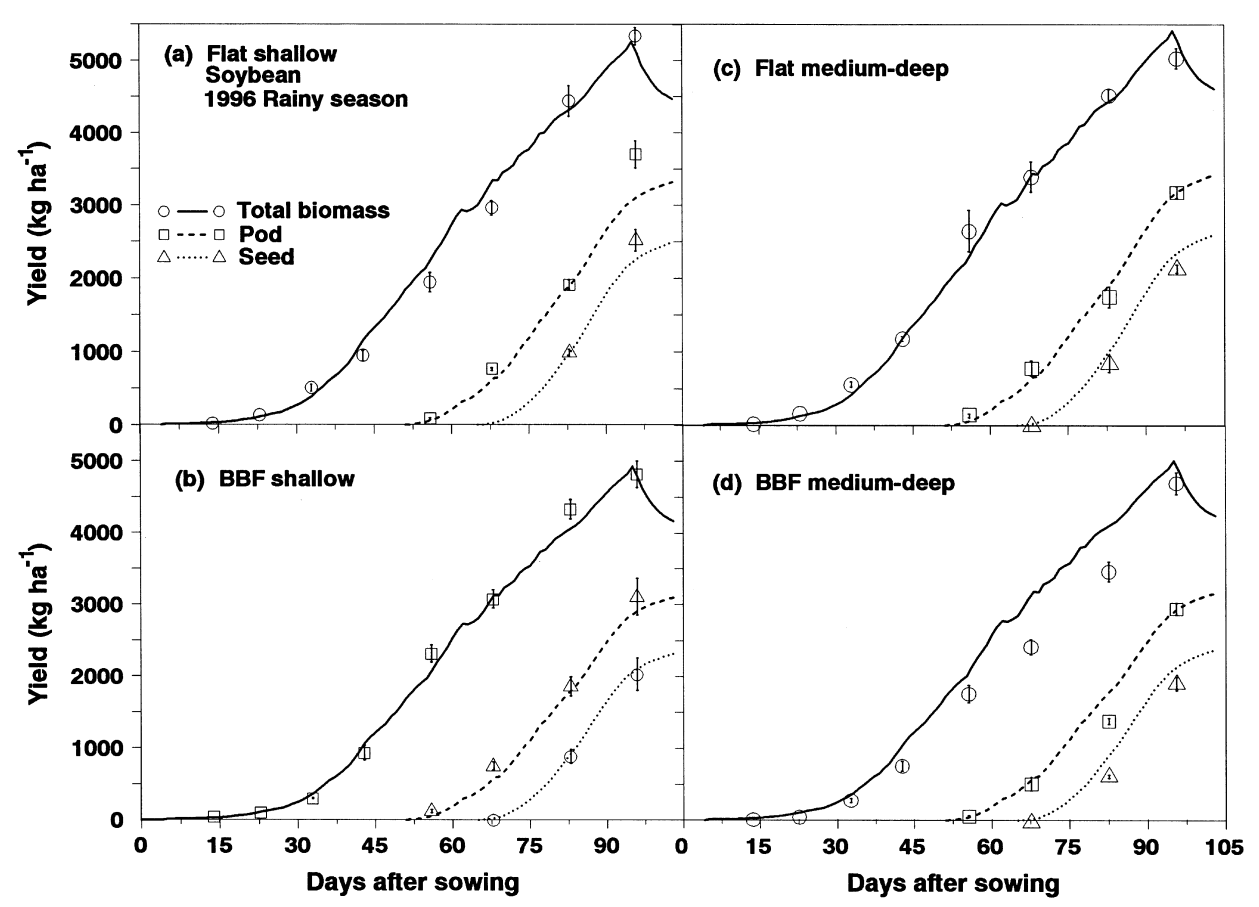

Fig. 4. Simulated (lines) and observed (data points) changes in total biomass, pod, and seed yield of soybean in the (a) flat shallow, (b) BBF shallow, (c) flat medium-deep and (d) BBF medium-deep treatments during the 1996-1997 season. Vertical bars on each data point are double the standard error of mean.

soybean growing period (Fig. 6(a)). In $70 \%$ of years, rainfall exceeded $600 \mathrm{~mm}$, which is greater than the water requirement of a 120-day soybean crop. During the post rainy period, rainfall ranged from 0 to $370 \mathrm{~mm}$. In $70 \%$ of years rainfall during the post rainy season exceeded $50 \mathrm{~mm}$.
The long-term simulation showed that runoff during the rainy season was greater for the medium-deep soil than for the shallow soil (Fig. 6(b)). For both soil depths, total runoff for the flat landform was greater than for the BBF landform. For the shallow soil there was a $70 \%$ probability that total seasonal runoff

Table 3

Observed (O) and simulated (S) yields $\left(\mathrm{kg} \mathrm{ha}^{-1}\right)$ of soybean (cv. PK 472) and chickpea (cv. ICCC 37) in various treatments during 1996-1997 season

\begin{tabular}{|c|c|c|c|c|c|c|c|c|}
\hline & \multicolumn{2}{|c|}{ Flat shallow } & \multicolumn{2}{|c|}{ BBF shallow } & \multicolumn{2}{|c|}{ Flat medium-deep } & \multicolumn{2}{|c|}{ BBF medium-deep } \\
\hline & $\mathrm{O}$ & $\mathrm{S}$ & $\mathrm{O}$ & $\mathrm{S}$ & $\mathrm{O}$ & $S$ & $\mathrm{O}$ & $\mathrm{S}$ \\
\hline & \multicolumn{8}{|c|}{ Soybean } \\
\hline Pod yield ${ }^{a}$ & 3140 & 3320 & 3110 & 3100 & 3190 & 3420 & 3000 & 3160 \\
\hline Seed yield & 2260 & 2490 & 2300 & 2310 & 2360 & 2600 & 2080 & 2380 \\
\hline \multirow[t]{2}{*}{ Biomass $^{\mathrm{a}}$} & 5350 & 4470 & 4810 & 4160 & 5050 & 4620 & 4730 & 4250 \\
\hline & \multicolumn{8}{|c|}{ Chickpea } \\
\hline Pod yield ${ }^{\mathrm{b}}$ & 1780 & 1350 & 1760 & 1330 & 2220 & 1810 & 2380 & 1950 \\
\hline Seed yield & 1020 & 1080 & 990 & 1080 & 1380 & 1500 & 1500 & 1660 \\
\hline Biomass & 1820 & 1900 & 1840 & 1830 & 2310 & 2440 & 2560 & 2590 \\
\hline
\end{tabular}

\footnotetext{
${ }^{\text {a }}$ Observed biomass and pod yields of soybean were estimated from growth analysis samples taken 10 days before the final harvest.

${ }^{\mathrm{b}}$ Observed pod yield of chickpea is estimated from the growth analysis samples taken 4 days before the final harvest.
} 


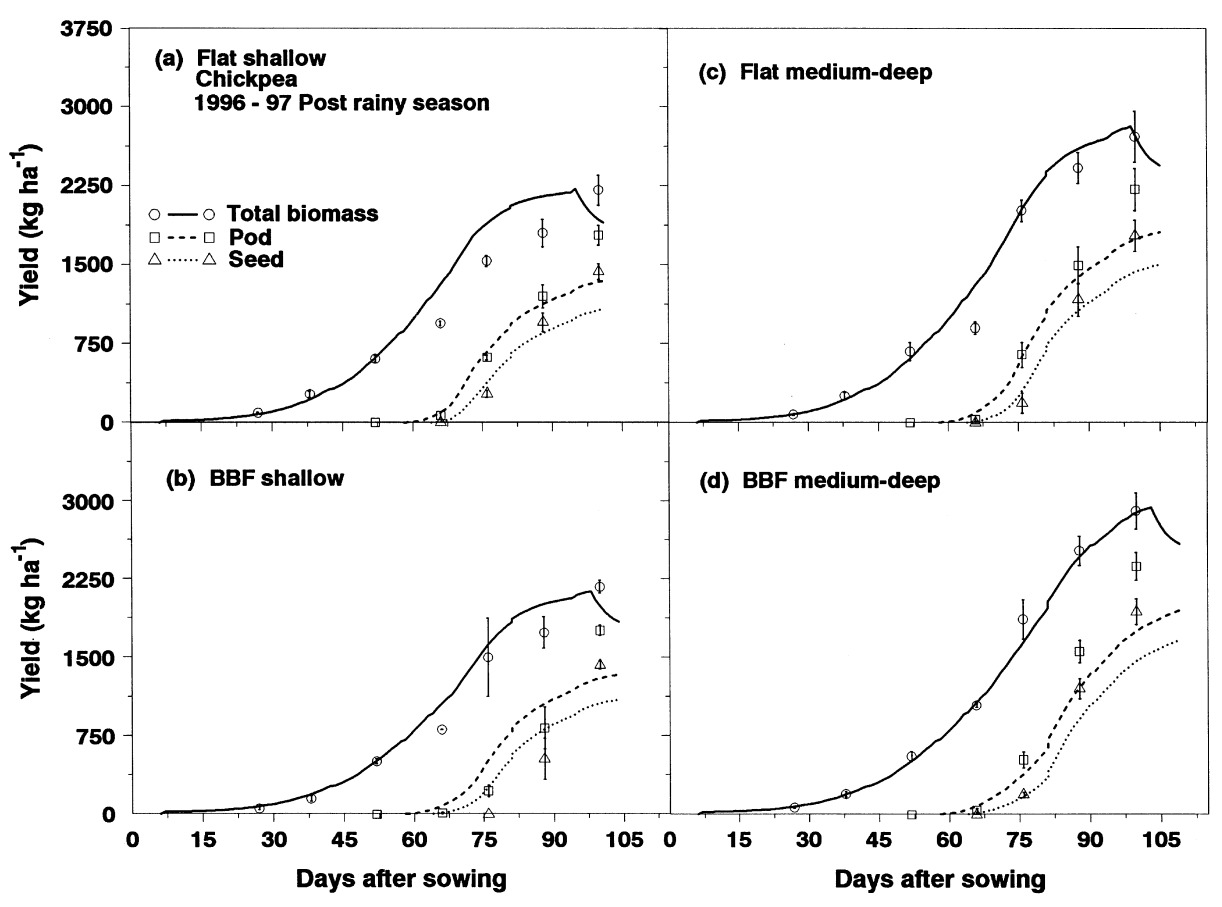

Fig. 5. Simulated (lines) and observed (data points) changes in total biomass, pod, and seed yield of chickpea in the (a) flat shallow, (b) BBF shallow, (c) flat medium-deep and (d) BBF medium-deep treatments during the 1996-1997 season. Vertical bars on each data point are double the standard error of mean.
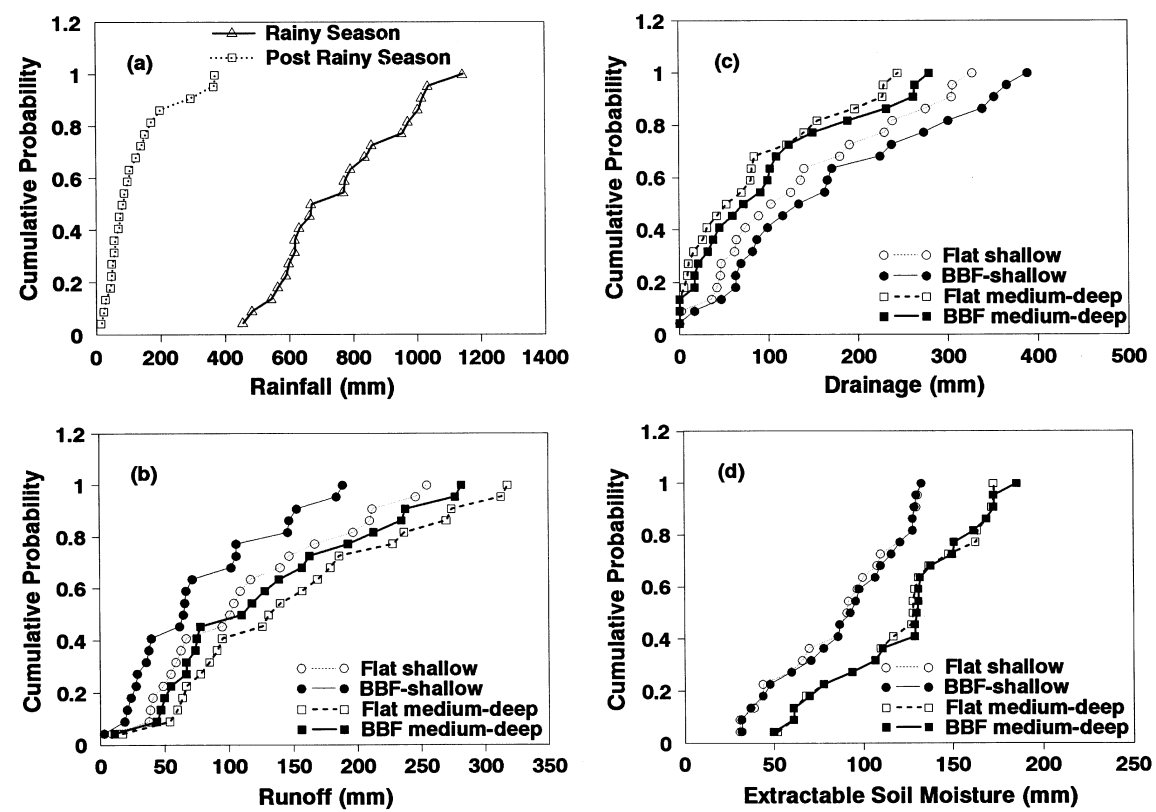

Fig. 6. Cumulative probability distribution for (a) rainy and post-rainy season rainfall; and the effect of landform treatments on (b) deep drainage and (c) surface runoff during the rainy season and (d) extractable soil moisture at the beginning of the post rainy season for two soil types. 
exceeded $60 \mathrm{~mm}$ (range $60-260 \mathrm{~mm}$ ) for the flat landform and $35 \mathrm{~mm}$ (range 35-190 mm) for BBF (Fig. 6(b)). Similarly for the medium-deep soil, total runoff during the rainy season exeeded $80 \mathrm{~mm}$ (range 80$320 \mathrm{~mm}$ ) on flat landform and $70 \mathrm{~mm}$ (range 70$280 \mathrm{~mm}$ ) on BBF at $70 \%$ probability. The simulation revealed that for most years, infiltration was increased for the BBF landform treatment for both soils, resulting in greater deep drainage compared to the flat landform treatment on the shallow soil. There was a $70 \%$ probability that total deep drainage exceeded $60 \mathrm{~mm}$ (range $60-330 \mathrm{~mm}$ ) for the flat landform and $80 \mathrm{~mm}$ (range $80-390 \mathrm{~mm}$ ) for BBF(Fig. 6(c)). For the medium-deep soil, deep drainage was comparatively smaller because of greater soil water-holding capacity. In $70 \%$ of the years, deep drainage of medium-deep soil ranged from 10 to $245 \mathrm{~mm}$ for the flat landform and $25-280 \mathrm{~mm}$ for BBF. Plant extractable water at sowing of chickpea ranged from 70 to $130 \mathrm{~mm}$ for the shallow soil and 100-190 $\mathrm{mm}$ for the medium-deep soil (Fig. 6(d)). In most years, soil profile of the BBF landform retained more extractable water compared to the flat landform.

These results for runoff and deep drainage identify impacts on soil erosion, water harvesting in surface tanks, ground water recharging, and loss of nutrients and other chemicals. Medium-deep soils have a greater potential for runoff and are prone to soil erosion. The BBF landform treatment can be used to regulate the flow of water on land surfaces to control soil erosion. Excess water could be stored in surface tanks for ground water recharging or for supplemental irrigation during the periods of water deficit. Shallow soils can also provide similar opportunities for water harvesting, but to a lesser extent because of more water percolations beyond the root zone. However, deep drainage can be captured through wells dug for supplemental irrigation of post rainy season crops. Greater losses of nutrients and other chemicals are expected to accompany deep drainage, thus causing ground water pollution on shallow soils. However, on medium-deep soil greater losses are expected in surface runoff rahter than deep drainage. It is recommended, therefore that in watersheds where soils have variable characteristics, site-specific management is needed to minimize soil erosion and pollution of ground and surface water in order to optimize crop productivity and resource -use efficiency.
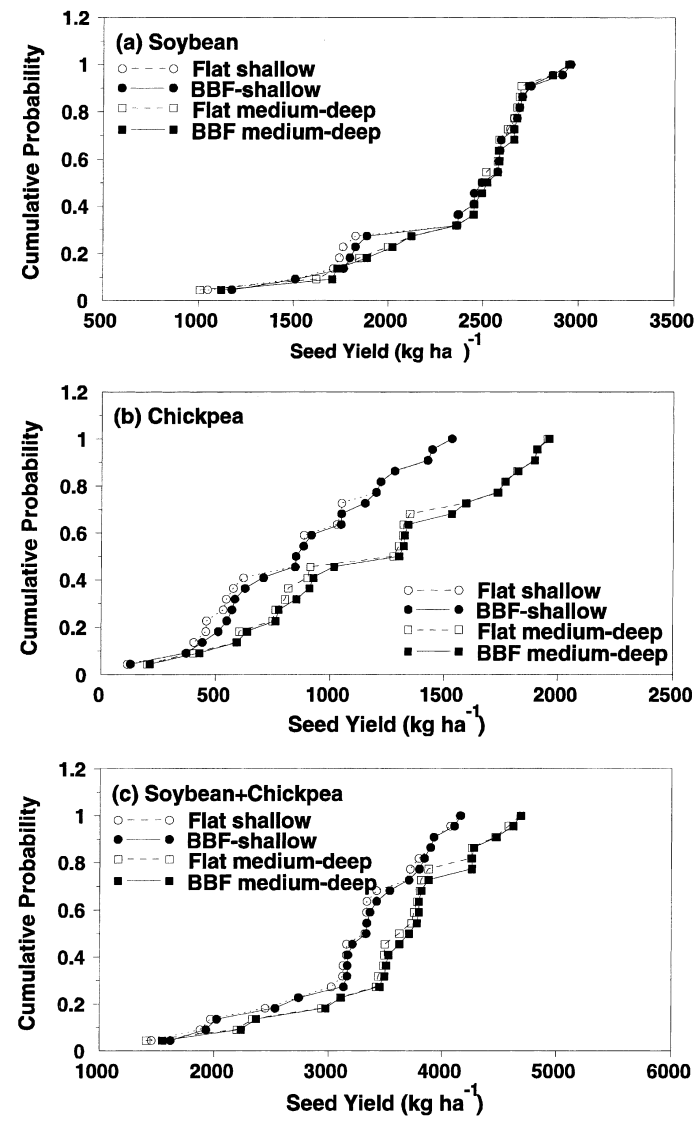

Fig. 7. Cumulative probability distribution of seed yield for (a) soybean, (b) chickpea and (c) soybean + chickpea for landform treatments on two soil types.

\subsection{Long-term analysis of crop yields}

Long-term simulation of soybean showed that at least a yield of $1000 \mathrm{~kg} \mathrm{ha}^{-1}$ can be obtained on Vertic Inceptisols in all years at Patancheru (Fig. 7(a)). In most years, soil depth and landform did not influence yield. However, during years of relatively low rainfall corresponding to yields less than $2400 \mathrm{~kg} \mathrm{ha}^{-1}$, yields were slightly higher on medium-deep soil compared to the shallow soil. Because of adequate availability of soil moisture in the rainy season, stochastic dominance analysis showed that no treatment was dominant in the higher yield range of soybean.

In contrast to soybean, chickpea yields were higher for the medium-deep soil than for the shallow soil (Fig. 7(b)), and the land surface treatments also had some effects on yield. There was a $70 \%$ probability 
that seed yield for the shallow soil exceeded $500 \mathrm{~kg} \mathrm{ha}^{-1}$ (range $500-1500 \mathrm{~kg} \mathrm{ha}^{-1}$ ) on the flat landform treatment and $580 \mathrm{~kg} \mathrm{ha}^{-1}$ (range 580 $1500 \mathrm{~kg} \mathrm{ha}^{-1}$ ) for the BBF treatment. For the medium deep soil, there was a $70 \%$ probability that seed yields exceeded $800 \mathrm{~kg} \mathrm{ha}^{-1}$ (range $800-1950 \mathrm{~kg} \mathrm{ha}^{-1}$ ) for the flat landform and $850 \mathrm{~kg} \mathrm{ha}^{-1}$ (range 850 $1960 \mathrm{~kg} \mathrm{ha}^{-1}$ ) for BBF. Based on stochastic dominance analysis, cumulative probability distribution functions for chickpea yield showed a clear dominance of strategies of medium-deep soil over the strategies of shallow soil in the entire yield range. On the shallow soil, because of better soil water storage in the BBF landform treatment, yields were marginally greater in most years compared to the flat landform treatment. For the shallow soil there was a $70 \%$ probability that the combined yields of soybean and chickpea were exceeded $3000 \mathrm{~kg} \mathrm{ha}^{-1}$ (range $3000-4150 \mathrm{~kg} \mathrm{ha}^{-1}$ ) for the flat landform and $3100 \mathrm{~kg} \mathrm{ha}^{-1}$ (range $3100-4150 \mathrm{~kg} \mathrm{ha}^{-1}$ ) for BBF. However, for the medium deep soil, there was a $70 \%$ probability that the yields were greater than $3450 \mathrm{~kg} \mathrm{ha}^{-1}$ for both landforms (range 3450$4700 \mathrm{~kg} \mathrm{ha}^{-1}$ ).

Low yields of chickpea for the shallow soil compared to the medium deep soil, were primarily attributed to the differences in available water-holding capacities of these soils. Greater yields of chickpea for BBF compared to flat landform for both soil types, were attributed to greater water conservation on BBF than flat landform in many years. These differences in chickpea yield were also reflected in greater productivity of the overall soybean and chickpea crop rotation system.

\section{Summary and conclusions}

Long-term simulation of the water balance showed that there was a $70 \%$ probability that total runoff from the Vertic Inceptisols was greater than $35 \mathrm{~mm}$ (range $35-320 \mathrm{~mm}$ ) and deep drainage greater than $60 \mathrm{~mm}$ (range 60-390 $\mathrm{mm}$ ) during the rainy period. The BBF landform increased infiltration of water for both a soils and increased the yields of chickpea especially for the shallow soil. In the absence of biotic stresses and any significant changes in the soil fertility, total productivity of the soybean-chickpea crop rotation system in
$70 \%$ of years exceeded $3000 \mathrm{~kg} \mathrm{ha}^{-1}$ (range 3000$4150 \mathrm{~kg} \mathrm{ha}^{-1}$ ) for the shallow soil and $3450 \mathrm{~kg} \mathrm{ha}^{-1}$ (range $3450-4700 \mathrm{~kg} \mathrm{ha}^{-1}$ ) for the medium-deep soil. Multi-year simulation results showed that greater runoff and deep drainage on Vertic Inceptisols in assured rainfall environments provide the opportunity for water harvesting in surface ponds as well as for recovering the deep drainage water. Crop yields can be substantially improved by increasing rainfall-use efficiency through appropriate land and water management practices in a watershed framework.

\section{Acknowledgements}

The authors acknowledge the International Consortium on Agricultural Systems Analysis (ICASA) for providing DSSAT v3 and for incorporating the chickpea model in the software. Assistance of Dr. S. Chandra, and M/s S. Ramakrishna, R Mukunda Reddy, N.V. Ratnau, S. Raghavendra Rao, M. Babu Rao, and B.N. Reddy, in the conduct of the field experiment and data collection and that of $\mathrm{Mr}$. K.N.V. Satyanarayana in typing this paper is also gratefully acknowledged. This article was submitted as article no. JA 2290 by the International Crops Research Institute for the Semi-Arid Tropics (ICRISAT). Mention of commercial products does not imply endorsement or recommendation by ICRISAT or the University of Georgia.

\section{References}

Alagarswamy, G., Virmani, S.M., 1996. Risk analysis of rainfed sorghum production at various levels of nitrogen fertilizer rate with CERES Sorghum Crop Simulation model. In: Ito, O., Johansen, C., Adu-Gyamfi, J.J., Katayama, K., Kumar Rao, J.V.D.K., Rego, T.J. (Eds.), Roots and Nitrogen in Cropping Systems of the Semi-arid Tropics. Japan International Research Center for Agricultural Sciences, Tsukuba, Japan, pp. 603-614.

Anderson, J.R., Dillon, J.L., Hardaker, J.B., 1977. Agricultural Decision Analysis. The Iowa State University Press, Ames, IA, USA, 344 pp.

Boote, K.J., Jones, J.W., Hoogenboom, G., 1997. Simulation of crop growth: CROPGRO model. In: Peart, R.M., Curry, R.B. (Eds.), Agricultural Systems Modeling. Marcel Dekker, New York, USA, pp. 651-692.

Bowen, W.T., Thornton, P.K., Hoogenboom, G., 1998. The simulation of cropping sequences using DSSAT. In: Tsuji, G.Y., Hoogenboom, G., Thornton, P.K. (Eds.), Understanding 
Options for Agricultural Production. Kluwer Academic Publishers, Dordrecht, pp. 313-327.

Caldwell, R.M., Hansen, J.W., 1993. Simulation of multiple cropping systems with CropSys. In: Penning de Vries, F.W.T., Teng, P., Metselaar, K. (Eds.), Systems Approaches for Agricultural Development. Proc. Int. Symposium, 2-6 December 1991, Bankok, Thailand. Kluwer Academic Publishers, Dordrecht. pp. 397-412.

Hunt, L.A., Pararajasingham, S., 1994. Genotype coefficient calculator. In: Tsuji, G.Y., Uehara, G., Balas, S. (Eds.), DSSAT v3, vol. 3, University of Hawaii, Honolulu, Hawaii, pp. 201232.

Hunt, L.A., Pararajasingham, S., Jones, J.W., Hoogenboom, G., Imamura, D.T., Ogoshi, R.M., 1993. GENCALC — Software to facilitate the use of crop models for analyzing field experiments. Agron. J. 85, 1090-1094.

IBSNAT (International Benchmark Sites Network for Agrotechnology Transfer), 1990. Technical Report 5: Documentation for the IBSNAT Crop Model Input and Output Files, Version 1.1. Department of Agronomy and Soil Science, College of Agriculture and Human Resources, University of Hawaii, Honolulu.

Keating, B.A., McCown, R.L., Wafula, B.M., 1993. Adjustment of nitrogen inputs in response to a seasonal forecast in a region of high climatic risk. In: Penning de Vries, F.W.T., Teng, P., Metselaar, K. (Eds.), Systems Approaches for Agricultural Development. Proc. Int. Symposium, 2-6 December 1991, Bangkok, Thailand. Kluwer Academic Publishers, Dordrecht, pp. 397-412.

Probert, M.E., Dimes, J.P., Keating, B.A., Dalal, R.C., Strong, W.M., 1998. APSIM's water and nitrogen modules and simulation of the dynamics of water and nitrogen in fallow systems. Agricultural Systems 56, 1-28.
Rego, T.J., Seeling, B., 1996. Long-term effects of legume based cropping systems on soil nitrogen status and mineralization in Vertisols. In: Ito, O., Johansen, C., Adu-Gyamfi, J.J., Katayama, K., Kumar Rao, J.V.D.K., Rego, T.J. (Eds.), Roots and Nitrogen in Cropping Systems of the Semi-arid Tropics. Japan International Research Center for Agricultural Sciences, Tsukuba, Japan, pp. 603-614.

Ritchie, J.T., 1998. Soil water balance and plant water stress. In: Tsuji, G.Y., Hoogenboom, G., Thornton, P.K. (Eds.), Understanding Options for Agricultural Production. Systems Approaches for Sustainable Agricultural Development. Kluwer Academic Publishers, Dordrecht, The Netherlands, pp. 41-54.

Singh, P., Virmani, S.M., 1996. Modeling growth and yield of chickpea (Cicer arietinum L.). Field Crops Res. 46, 41-49.

Singh, P., Alagarswamy, G., Pathak, P., Wani, S.P., Hoogenboom, G., Virmani, S.M., 1999. Soybean-chickpea rotation on VerticInceptisols: 1. Effect of soil depth and landform on light interception water balance and crop yields. Field Crops Res. 63, 211-224.

Thornton, P.K., Hoogenboom, G., Wilkens, P.W., Bowen, W.T., 1995. A computer program to analyze multiple-season crop model outputs. Agron. J. 87, 131-136.

Timsina, J., Singh, U., Singh, Y., 1997. Addressing sustainability of rice-wheat systems: analysis of long-term experimentation and simulation. In: Kropff, M.J., Teng, P.S., Aggarwal, P.K., Bouma, J., Bouman, B.A.M., Jones, J.W., Van Laar, H.H. (Eds.), Application of Systems Approaches at the Field Level, vol. 2. Kluwer Academic Publishers, Dordrecht, pp. 383-397.

Tsuji, G.Y., Uehara, G., Balas, S. (Eds.), 1994. DSSAT v3, vol. 1, 2, and 3. University of Hawaii, Honolulu, Hawaii.

Wilkerson, G.G., Jones, J.W., Boote, K.J., Ingram, K.T., Mishoe, J.W., 1983. Modeling soybean growth for management. Trans. ASAE 26, 63-73. 